TAO, Vol. 12, No. 3, 525-536, September 2001

\title{
MIR Space Station Topside Sounding near Taiwan
}

\author{
Sergei A. Pulinets ${ }^{1}$, Jann-Yenq Liu ${ }^{2, *}$, Yu-Jung Chuo ${ }^{2}$, Nikolai P.Danilkin ${ }^{3}$, \\ Depuev Victor Kh. ${ }^{1}$, and Nadezhda G. Kotonaeva ${ }^{3}$
}

(Manuscript received 13 June 2000, in final form 23 April 2001)

\begin{abstract}
First results from ionospheric topside sounding data received at Taiwan National Central University are reported. The sounding was accomplished from the topside sounder on the Russian MIR. The topside ionograms and calculated vertical profiles of electron concentration were compared with corresponding bottomside ionograms and profiles. The total composed vertical profiles were obtained. A very good correspondence between the topside and bottomside ionospheric data, both for critical frequency and peak height was achieved and a total composite vertical profile was thus obtained. The scaled local plasma (ordinary cutoff) and critical frequencies, as well as topside profiles along the station pass, permit the position and shape of the northern crest of the equatorial anomaly to be determined. The low orbit of MIR space station gives the unique possibility to check the peak height models of the ionosphere due to ability of in-situ and remote sounding measurements simultaneously, especially in periods when the station is inside the peak.
\end{abstract}

(Key words: Topside sounding, Electron concentration, Ionosphere, Peak height)

\section{INTRODUCTION}

The equatorial anomaly is one of the most dynamic and unpredictable regions of the Earth's ionosphere. Its behavior to a great extent affects the global radiowave propagation, including communication, broadcast and navigational systems. The global monitoring and control of the equatorial anomaly is a very complex task. Groundbased ionosondes can provide information only about the land regions, which are a minor part of the earth's surface. Recently developed GPS TEC measurements give information only about the total electron

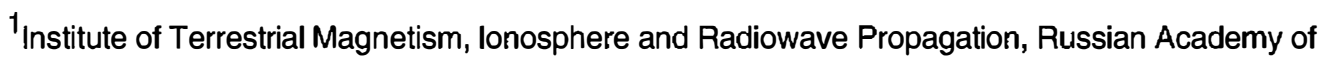
Sciences, Troitsk, Russia

${ }^{2}$ Institute of Space Sciences, National Central University, Chung-Li, Taiwan, ROC

3 Institute of Applied Geophysics, Moscow, Russia

* Corresponding author address: Prof. Jann-Yenq Liu, Institute of Space Science, National Central University, Chung-Li, Taiwan 32054, ROC; E-mail: jyliu@jupiter.ss.ncu.edu.tw 
content but not on the structure of the equatorial anomaly, including plasma irregularities of different scales which have a major effect on radiowave propagation. Low altitude satellites with topside sounder - are the only alternative. The Alouette 1 and 2, ISIS 1 and 2, Intercosmos19 , ISS-B and COSMOS 1809 have proved their effectiveness for global ionosphere monitoring possibilities (Pulinets and Benson 1999). Many discoveries resulted from these topside sounders.

The installation of the topside sounder onboard the Russian MIR space station provides a new opportunity for global studies of the Earth's ionosphere. The topside sounder onboard the MIR station is a modified replica of those installed onboard the Intercosmos-19 and COSMOS 1809 satellites described in Pulinets (1989). It offers possibility to record data for global monitoring regime or to transmit them directly to a receiving station when passing within $2500 \mathrm{~km}$ of the station.

\section{RECEIVING POINT AT CHUNG-LI}

The first test passes were received at Institute of Space Science, National Central University, Chung-Li, Taiwan, from 21-25 April, 1999. Projections of the MIR station passes on the horizontal plane are shown in Fig.1. Passes 3245 (Date: 21.04.1999) and 3276 (Date: 23.04.1999), as well as 3246 (Date: 21.04.1999) and 3277 (Date: 23.04.1999) had practically the same trajectories, therefore they overlap in the figure. Reception was conducted with the help of 5element Yagi antenna and AR-3000A Professional Monitor Receiver, the telemetric signal was recorded on a PC Pentium II computer in the form of *.wav file, and then processed with the specially designed software. The data processing consisted of several stages: signal decoding and ionograms selection, ionogram scaling, and topside profile calculation. Each step was controlled by a specific software program. The sequence of ionograms received from pass 3482 is presented in Fig. 2. The signal amplitude is color coded, horizontal axis represents the sounding frequency and the vertical one - represents the virtual height with zero corresponding to the satellite height.

\section{TOPSIDE SOUNDING BACKGROUND}

The topside sounder installed onboard the MIR station worked within the frequency band $0.3-15.95 \mathrm{MHz}$ on 338 fixed frequencies. The frequency step within the band $0.3-1.5 \mathrm{MHz}$ was $25 \mathrm{kHz}$, and for the rest of the frequency band it was $50 \mathrm{kHz}$. In the direct transmission mode the consecutive soundings were conducted every $8 \mathrm{~s}$, and in the global monitoring mode every $32 \mathrm{~s}$. The topside sounder was installed at "Priroda" module. The V-shaped dipole was used for transmission and receiving the signals. Taking into account the very complex configuration of the signal reflected from the ionosphere. The maximum length of one dipole was $25 \mathrm{~m}$. the photo pf the dipole installed onboard the MIR space station is presented in Fig. 3.

The main difference between topside and bottomside sounding is that the transmitting and receiving antennas of the topside sounder are immersed into the ionospheric plasma, so the interaction of the emitted wave with the plasma starts immediately in the satellite vicinity. According to the wave dispersion relation for a magnetized plasma, electromagnetic waves of 


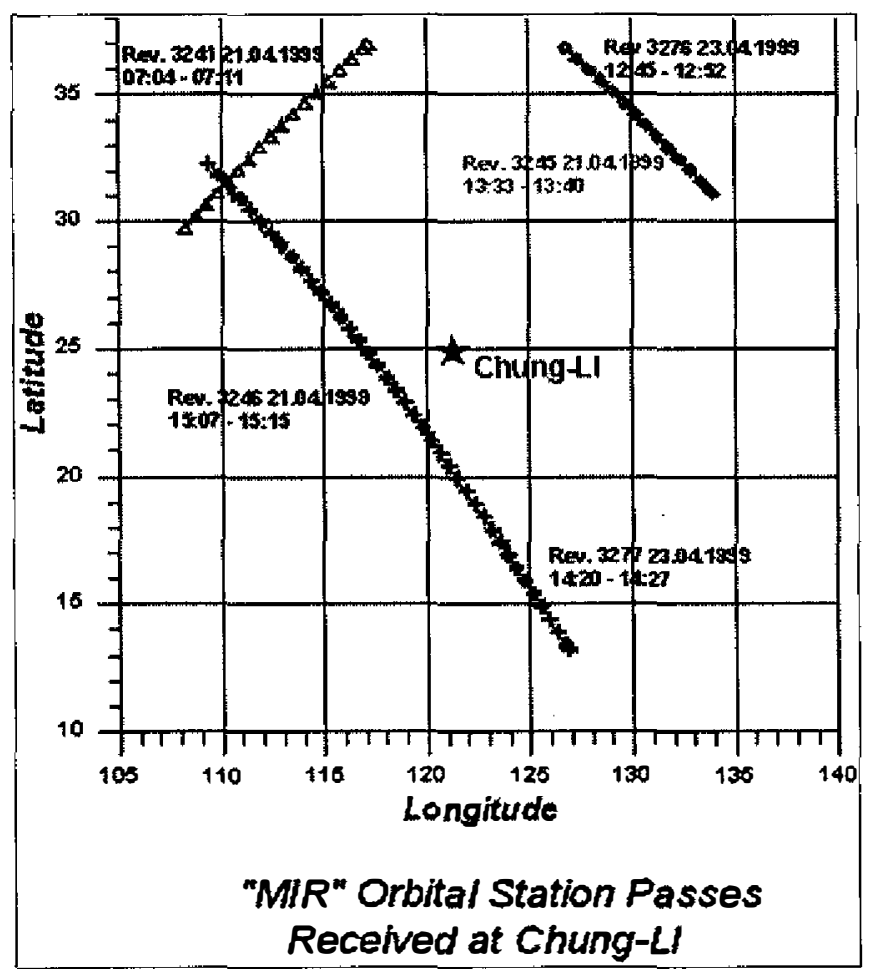

Fig.1. Cartesian projections (geodetic latitude-longitude) of the MIR station orbits received at Chung-Li.

different polarization can propagate in a plasma only at frequencies higher than the so-called cut-off frequencies, which are:

$$
f_{Z}=\frac{\sqrt{4 f_{N}^{2}+f_{H}^{2}}}{2}-\frac{f_{H}}{2} \text { - left-hand polarized slow extraordinary mode }
$$

$f_{N}$ (local electron plasma frequency)- left hand polarized fast ordinary mode

$$
f_{X}=\frac{\sqrt{4 f_{N}^{2}+f_{H}^{2}}}{2}+\frac{f_{H}}{2} \text { - right-hand polarized fast extraordinary mode }
$$

The group velocities of the waves near the cut-off frequencies are very low, so they can effectively interact with the ambient plasma, exciting plasma turbulence in the form of plasma resonances, which are observed on topside ionograms as spikes. With increasing frequency, the group velocity increases, approaching the propagation velocity of the electromagnetic wave in a vacuum.

As the reflection point is approached, with increasing electron density below the satellite, the group velocity decreases to 0 and changes sign. On topside ionograms the total echo group delay at each frequency to this point of reflection is converted to a "virtual height" by dividing 

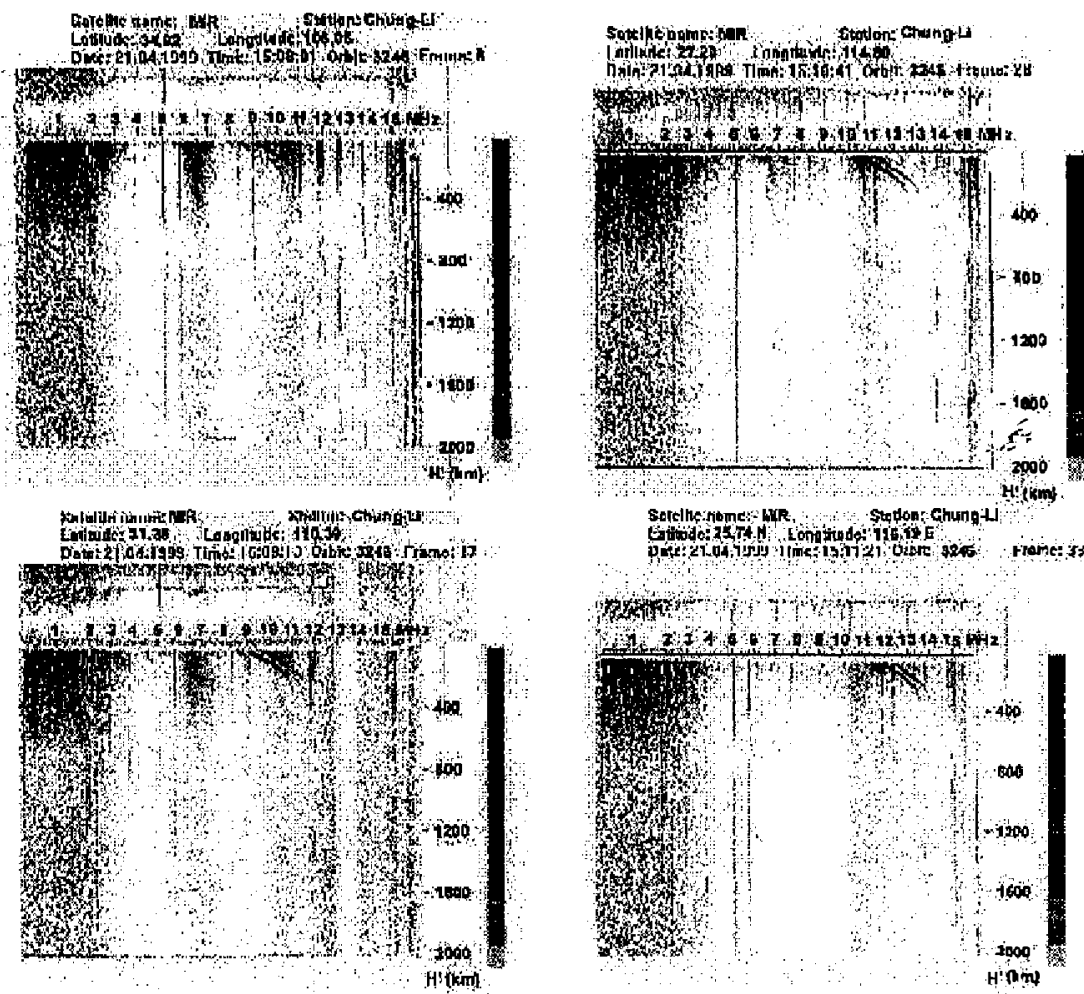

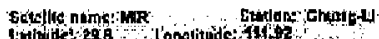

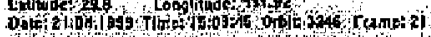

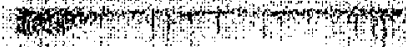

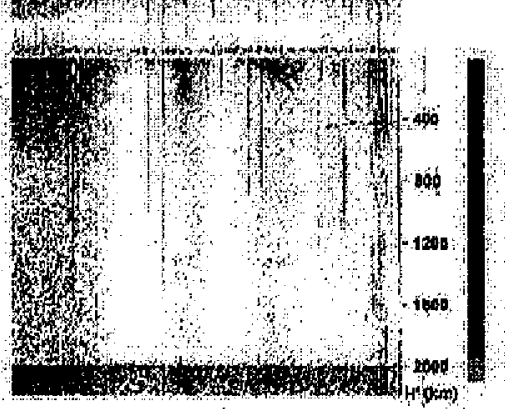

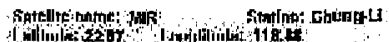

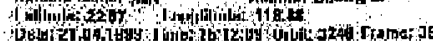

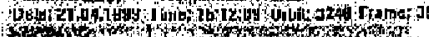

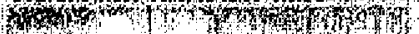

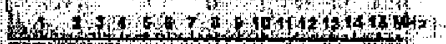

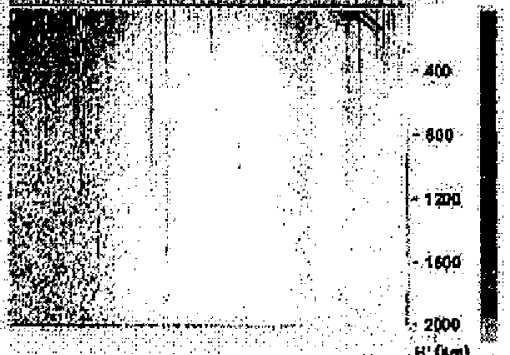

Fig. 2. Selected topside ionograms between LAT: $34.82^{\circ} \mathrm{N}$, Long: $106.06^{\circ} \mathrm{E}$ and LAT: $22.87^{\circ} \mathrm{N}$, Long: $118.88^{\circ} \mathrm{E}$, received at Chung-Li during orbit 3246 on 21 April 1999 between 07:08:01 and 07:12:09 UT. The local time difference is $+8 \mathrm{~h}$. The top part of every ionogram represents the level of noises at the receiver input measured before pulse transmission. 


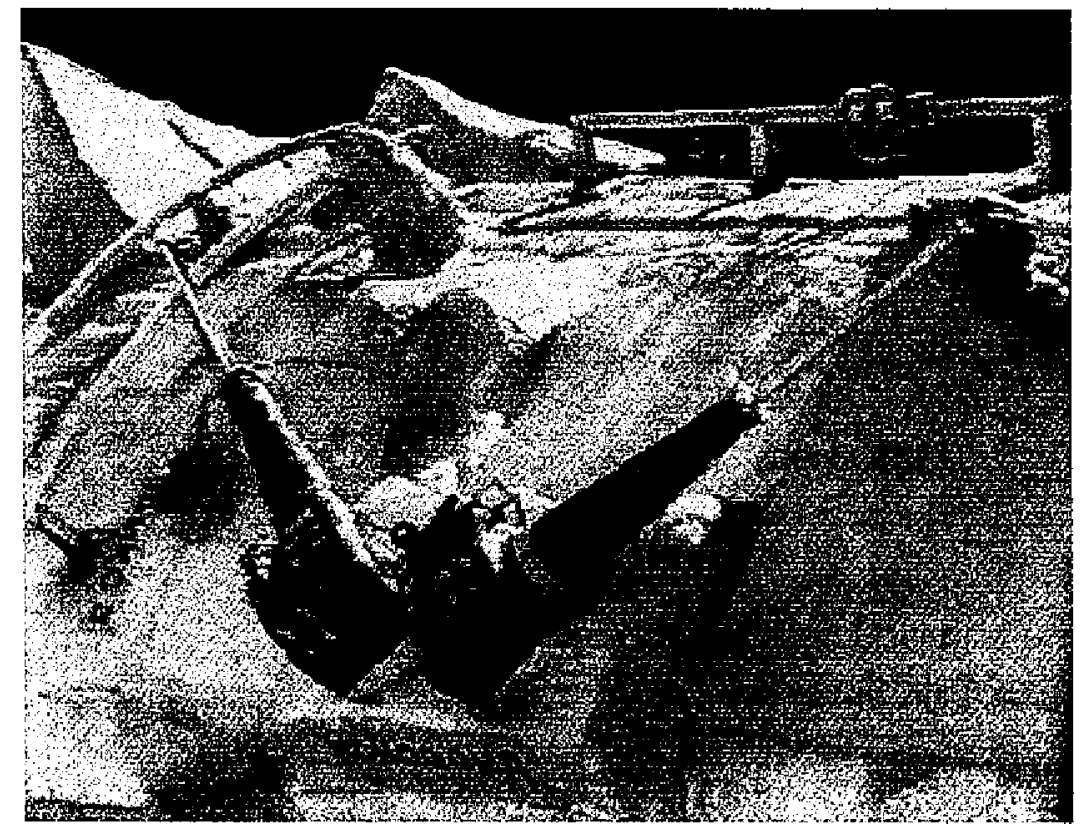

Fig. 3. Topside sounder dipole antenna installed onboard the "Priroda" module of the MIR space station.

by 2 and then multiplying by the free-space light velocity. In order to obtain the real electron density profile it is necessary to solve the problem of the group path $p^{\prime}(f)$ integral (Jackson 1969 a). During the last few years, the Jackson algorithm was improved by Denisenko et al. (1998) with the use of the regularization technique. In addition, they proposed an algorithm to calculate the bottomside profiles from the ground reflection trace on topside ionograms.

The local plasma density could be determined by two techniques: scaling of local plasma resonance stimulated by the topside sounder radiopulse transmitter and scaling of ordinary mode cutoff. Taking into account the well known relationship between the main plasma resonances and cutoff frequencies (Benson 1972, 1977), the corresponding frequencies could be determined even more precisely than the topside sounder frequency step, which equals $50 \mathrm{kHz}$ in frequency range higher than $1.5 \mathrm{MHz}$.

\section{TOPSIDE AND BOTTOM SIDE VERTICAL PROFILES COMPARISON}

The presence of the ground-based digisonde portable sounder (DPS) vertical sounder gave the wonderful opportunity to reconstruct the total vertical profile of electron concentration from ground to the space station height, including the most interesting main maximum of the electron concentration. For this purpose two satellite ionograms closet to Chung-Li were selected from the pass 3246. They are presented in Fig. 4. The corresponding bottom side ionograms are presented in Fig. 5. Taking into account the difference in longitude (local time), 


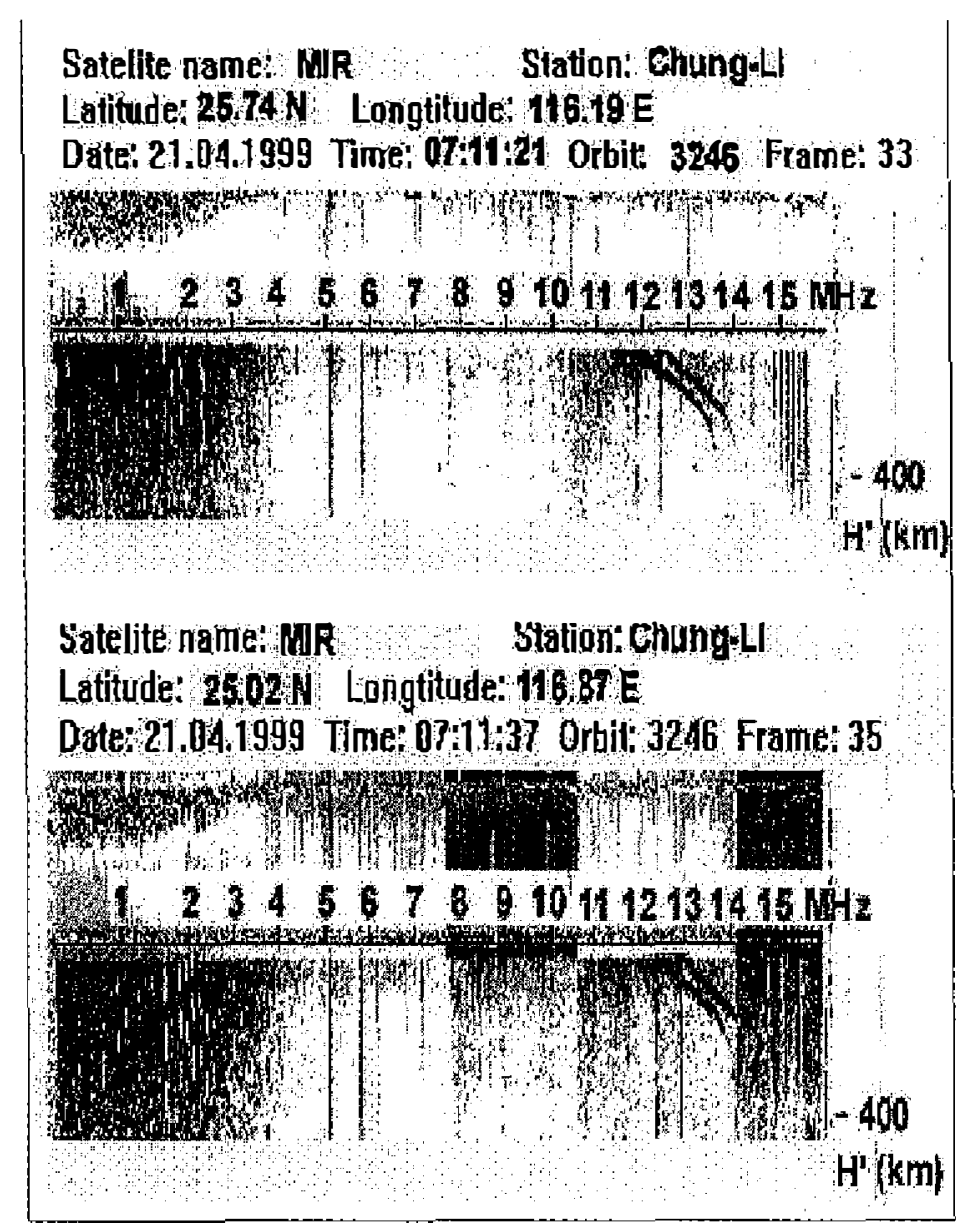

Fig. 4. The topside ionograms selected for comparison with groundbased sounding data. The top part of every ionogram represents the level of noises at the receiver input measured before pulse transmission.

the critical frequencies practically coincide, which confirms the validity of topside sounding technique. But this was always the subject of discussion, so the precision of peak height determination from topside ionograms (Jackson 1969b). Topside and bottom side profiles comparisons were made for different latitudes (Pasheva et al. 1984, Ben'kova et al. 1985), and satisfying the results were obtained. The MIR station gives the perfect opportunity to check the validity of the topside profiles calculation algorithm because of two factors: a) low altitude of the MIR station orbit makes the profiles short and calculations more precise, b) again due to the low altitude sometimes the station will fall directly into the peak of electron concentration, therefore the peak height and peak electron density could be determined from the in situ measurements. This situation was realized twice during MIR station passes received at Chung-Li.

Taking into account the above discussion, it is interesting to compare the calculated topside 
Lwe11 Di gisonde

政

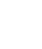
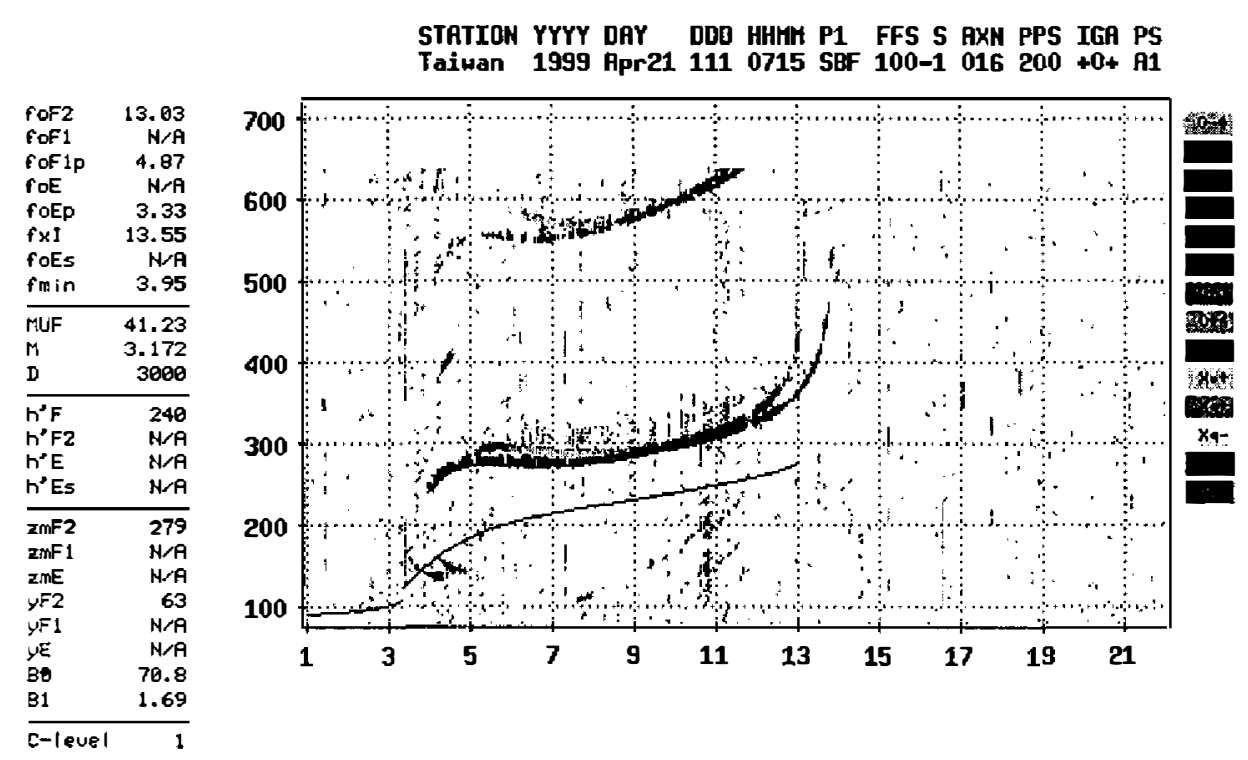

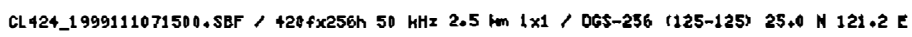

STATION YYYY DAY DOD HHMM P1 FFS S RXN PPS IGA PS Taiwan 1999 Apr21 1110700 SBF 100-I $016200+0+$ A1

\begin{tabular}{|c|c|}
\hline $\begin{array}{l}\text { fof2 } \\
\text { foF } 1 \\
\text { foF1p } \\
\text { foE } \\
\text { foEp } \\
\text { fXI } \\
\text { foEs } \\
\text { fmin }\end{array}$ & $\begin{array}{r}13.53 \\
\text { N/A } \\
4.93 \\
3.71 \\
3.39 \\
14.10 \\
4.85 \\
3.55\end{array}$ \\
\hline $\begin{array}{l}\text { MUF } \\
M \\
D\end{array}$ & $\begin{array}{r}42.81 \\
3.171 \\
3000\end{array}$ \\
\hline $\begin{array}{l}n^{\prime} F \\
r^{\prime} F 2 \\
r^{\prime} E \\
n^{\prime} E s\end{array}$ & $\begin{array}{l}280 \\
N / A \\
145 \\
129\end{array}$ \\
\hline $\begin{array}{l}z m F 2 \\
z m F 1 \\
z m E \\
y F 2 \\
y F 1 \\
y E \\
B E \\
B 1\end{array}$ & $\begin{array}{r}291 \\
N / R \\
111 \\
75 \\
N / A \\
20 \\
73.7 \\
2.56\end{array}$ \\
\hline
\end{tabular}

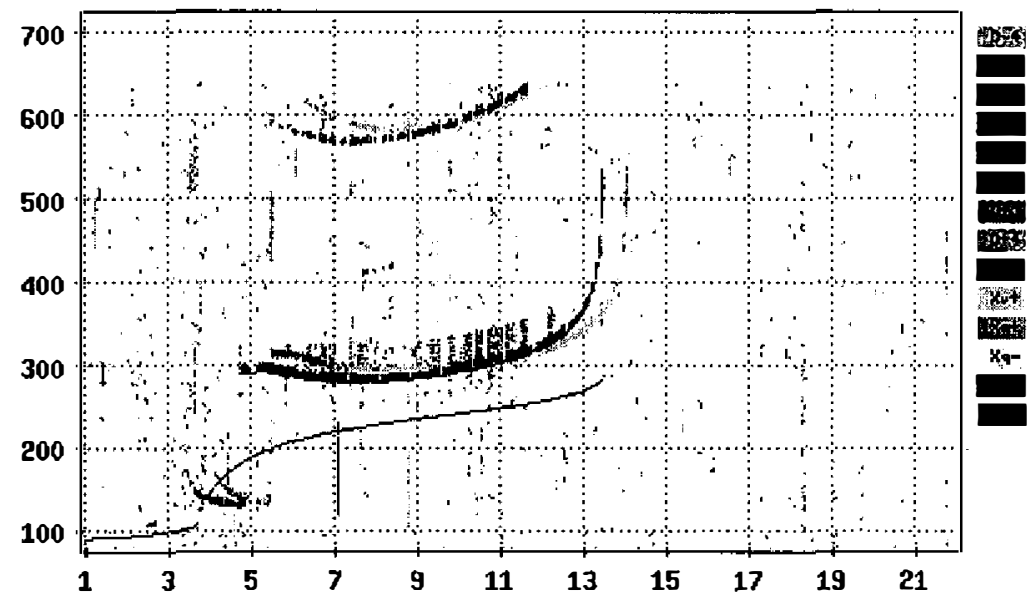

CL424_1999111070000.SBF / 420 $\times 256 \mathrm{~h} 50 \mathrm{kHz} 2.5 \mathrm{~km} 1 \times 1 / 065-256$ (125-125) 25.0 N $121.2 \mathrm{E}$

Fig. 5. Bottomside ionograms obtained from DPS during MIR station pass on April 21, 1999. 
and bottomside vertical profiles of electron concentration. For this purpose the topside profile closest in latitude to Chung-Li $\left(24.9^{\circ} \mathrm{N}\right)$ was selected. The MIR station latitude during the corresponding sounding was $25.07^{\circ} \mathrm{N}$. The combined topside-bottom side profiles are presented in Fig. 6 (blue - bottomside profile, red -topside profile). The topside profile calculation was made using the improved Jackson algorithm (Denisenko and Sotsky 1987) of topside profile reconstruction (Jackson 1969a). One can observe the perfect coincidence both in electron concentration and in peak height determination by both techniques. This comparison provides a level of coincidence to further use the topside profiles to determine the electron concentration and peak height values along the station pass and to determine the equatorial anomaly shape and the crest position.

\section{EQUATORIAL ANOMALY PARAMETERS DERIVED FROM TOPSIDE SOUNDING DATA}

The main advantage of an artificial satellite is its movement along the orbit. It provides a possibility for global studies of the Earth's ionosphere. During a short period of time it is possible to reconstruct the main ionospheric structures including the equatorial anomaly. It is possible to deduce the topside ionosphere vertical structure from the satellite height down to the F-layer peak. Sometimes the ground reflections provide the possibility to reconstruct the bottomside ionosphere. Topside latitudinal cuts give very precisely the latitudinal position of the equatorial anomaly crests. The peculiarity of the MIR station is its low orbit height in

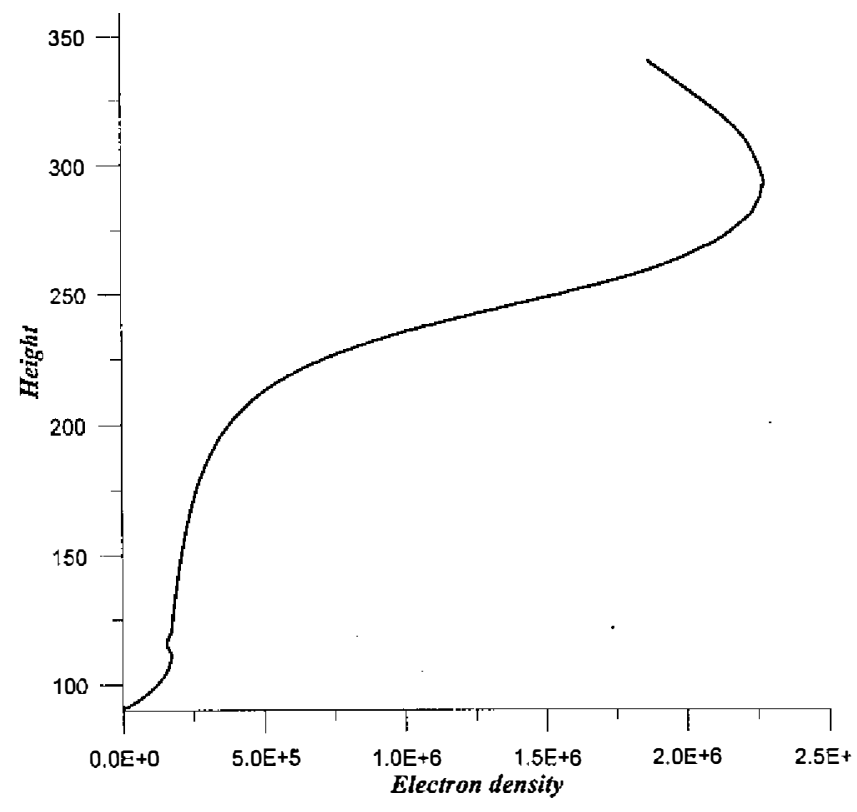

Fig. 6. Combined topside-bottom side profile of electron concentration, April 21 1999, 07-15 UT based on a MIR station over-flight the DPS groundbased sounder at Chung-Li, Taiwan $\left(24.9^{\circ} \mathrm{N}, 121.1^{\circ} \mathrm{E}\right)$. 
comparison with the F-layer peak altitude. Sometimes, and especially in the equatorial anomaly crests or during strong geomagnetic disturbances, the station falls under the peak and provides a unique opportunity never achieved before: under-peak sounding from a satellite. An example of the station immersion into the crest is shown in Fig. 7. The top panel presents the

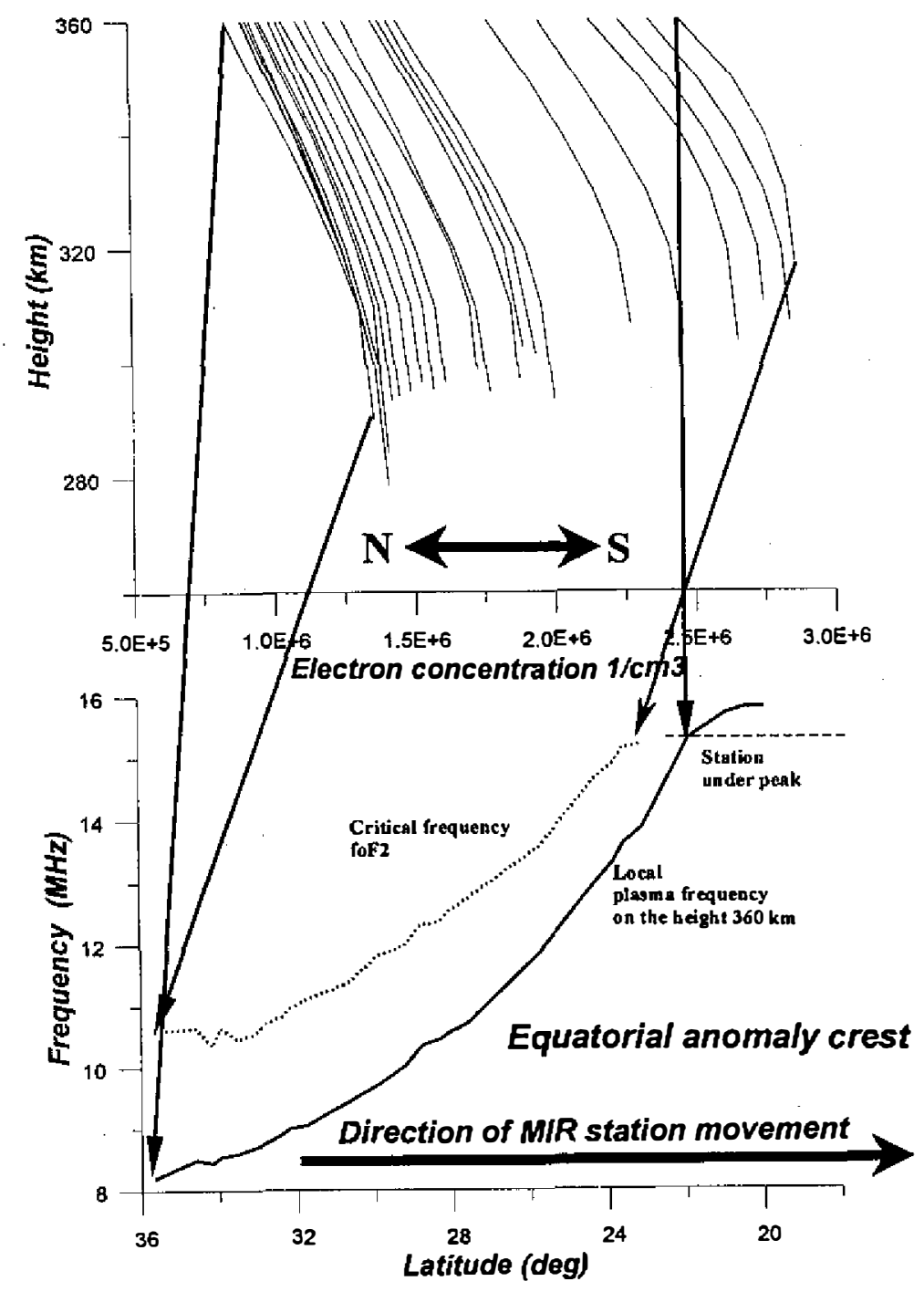

Fig.7. The sequence of topside profiles derived from topside ionograms (top panel) while moving the MIR station from North to South and equatorial anomaly crest parameters along latitude (bottom panel) from in situ measurements (bold line) and scaled critical frequency (dashed line). Extreme top and bottom points on $\mathrm{N}(\mathrm{h})$ topside profiles correspond to local plasma and critical frequencies on the bottom curves respectively. 


\section{MIR "PRIRODA" module}

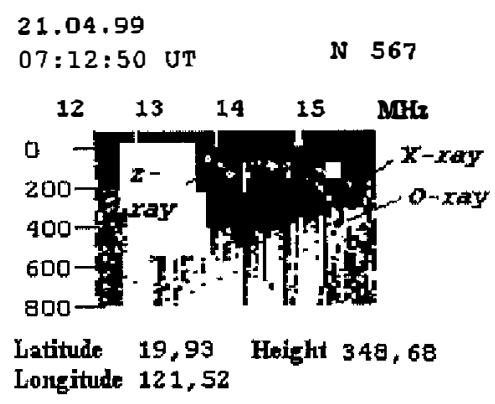

a
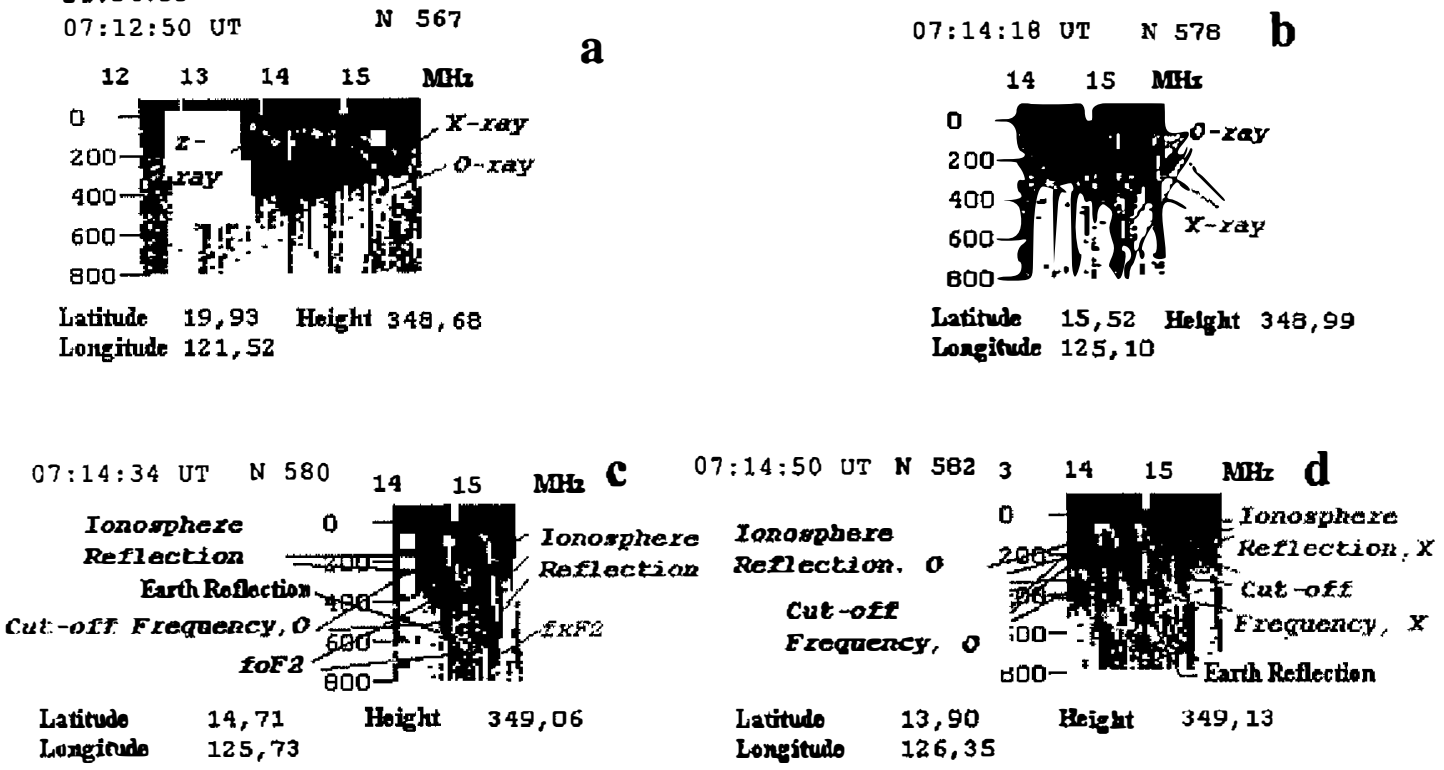

Fig. 8. The sequence of topside ionograms (fragments with reflection traces) in onboard memory recording mode during MIR station entering into the peak of F2-layer of the ionosphere.

sequence of the topside profiles (from the left to the right) while station is moving from north to south. One can observe the peak density $\mathrm{N}_{\mathrm{m}} \mathrm{F} 2$ and peak height $\mathrm{H}_{\mathrm{m}} \mathrm{F} 2$ while approaching the crest. The bottom panel presents the local (in-situ) plasma frequency scaled from the cutoff frequencies from topside ionograms (bold line) in comparison with critical-frequency $f_{0} F 2$ (dashed line). It is clearly seen that due to the low station orbit while approaching the anomaly crest the local frequency merged with critical one and even became higher than it, which means that the station first reached the F-layer peak height, and then moved under it. The under-peak ionograms were obtained from the station onboard recorder because the station was out of range of direct transmission on this part of the orbit. The fragments of the ionograms where the reflections traces are observed are presented in Fig. 8. Figure 8a shows the topside reflections very close to the upper frequency limit of the topside sounder. In the Fig. $8 \mathrm{~b}$ one can see the moment when the station is just within the peak of the F2-layer. There are no propagation traces but only the plasma resonances with frequencies corresponding to the local plasma and upper hybrid frequencies. And in this case the local plasma frequency corresponds to the critical frequency of the F2-layer. The last two ionograms correspond to the case when the station was under the peak. The main indicator is the ground-reflected traces. One can see that the frequencies of ground-reflected traces are lower than the frequencies of the $\mathrm{O}$ and $\mathrm{X}$ races. Explanation of this situation is given in Fig. 9, where the schematic presentation of different ray propagation in case of station under the peak is shown. Figure 9 hypothetic 


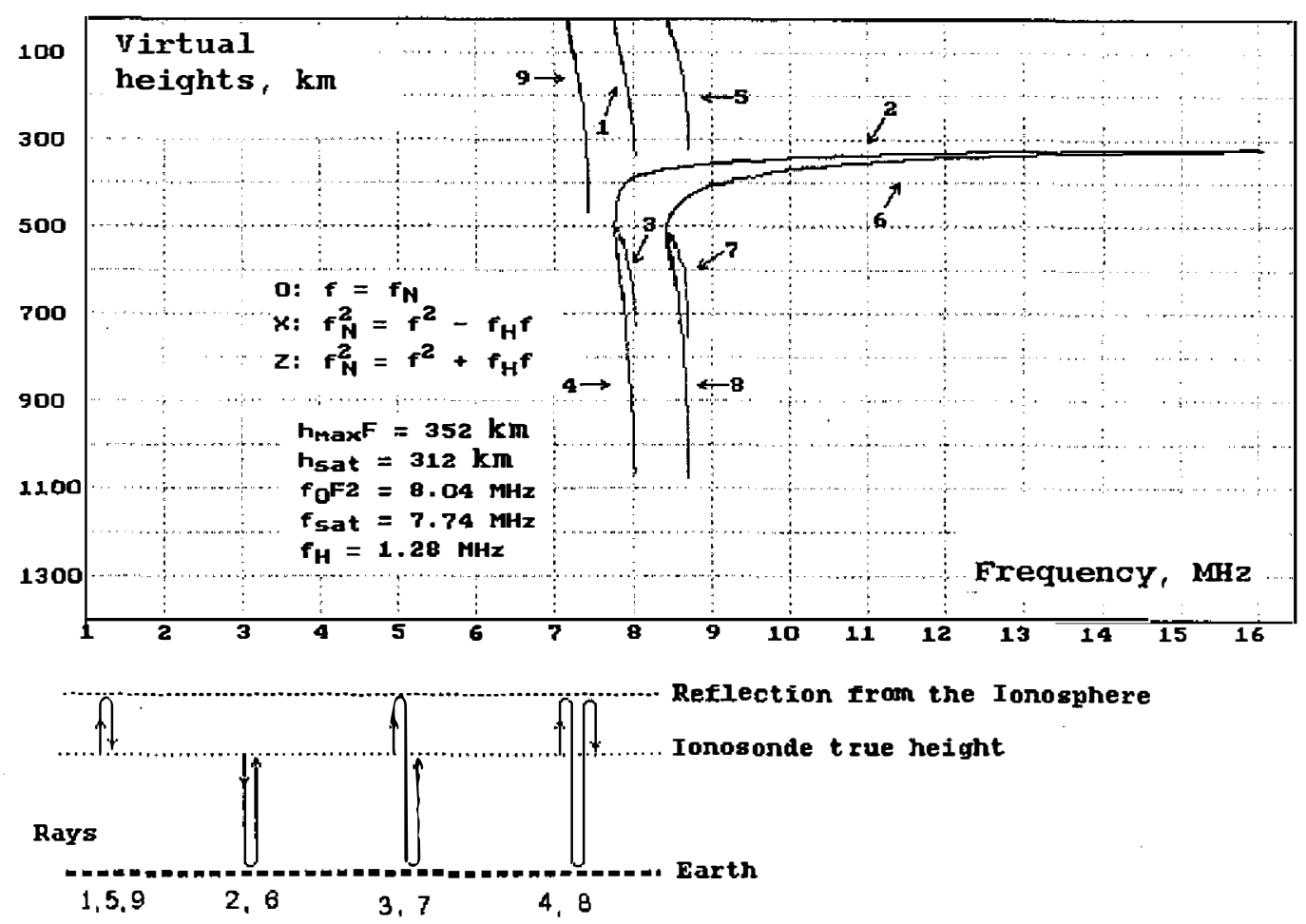

Fig. 9. Schematic presentation of the radiowave propagation traces while MIR station is under the peak of F2-layer of the ionosphere.

traces could be identified on the ionogram obtained for the sounder position under the peak of F2-layer. The first four correspond to the ordinary wave propagation: 1- up to the F-layer peak and back to the sounder, 2 - ground-reflected traces, 3 - the sum of 1 and 2 traces - up to the peak, down to the ground, back to the sounder, and finally, 4 - trace 3 plus one more 1 . The configuration of traces 4-8 corresponds to the same one as for ordinary mode, except for its extraordinary mode propagation. And, finally, the 9-th trace corresponds to the Z-mode propagation from the sounder up to the peak and back. The $\mathrm{O}$ and $\mathrm{X}$ reflections from the layer above the station, as well as ground reflections could be identified on the experimental ionograms $8 \mathrm{c}$ and $8 \mathrm{~d}$. A more detailed description of the model of under peak sounder wave propagation and other different examples of under peak propagation is given in (Danilkin 1999, 2000).

The examples shown in Fig. 8 demonstrate that the critical frequency could be determined even in cases when the ionospheric sounder is situated under the peak of the F-layer. We have simultaneously the bottomside and topic ionograms folded together, and the knuckle line is situated at the height of the space station.

\section{CONCLUSION}

The present paper demonstrates the capabilities abilities of the ionospheric sounding from 
low orbiting platforms. This kind of sounding is especially interesting when the station orbit altitude is in the vicinity of the peak height of the Earth's ionosphere to show what happens in the region of equatorial anomaly. The combination of bottom side and topside soundings provides an excellent opportunity to check the ionospheric peak parameters (density, height and peak shape). The satellite movement and critical frequency mapping give the exact position of the crests and trough of the equatorial anomaly. The cases when the station orbit was under the peak of F2-layer demonstrated that the peak parameters could be determined even in such situations. These experiments demonstrated that iononspheric sounding could be used on inhabited orbital stations, for example, the International Space Station.

Acknowledgments The work has been supported by the INTAS grant N97-1372 and NSC 89-2111-M-008-020-AP9.

\section{REFERENCES}

Ben'kova N. P., E. F. Kozlov, N. A. Kochenova, N. I. Samorokin, and M. D. Flige, 1985: Height-latitude distribution of the electron concentration in subauroral ionosphere by the data of Intercosmos-19 satellite and ground-based ionospheric stations. Geomagnetism and Aeronomy, 25, No.6, 893-899.

Benson R. F. 1972: Ionospheric plasma resonances: time durations vs. latitude, altitude, and $\mathrm{f}_{\mathrm{N}} / \mathrm{f}_{\mathrm{H}}$. Planet. Space Sci., 20, 683-706.

Benson R. F., 1977: Stimulated plasma waves in the ionosphere. Radio Sci., 12, 861-878.

Danilkin N. P., 1999: Synthesis of the topside ionograms under the presence of isolated irregularities in the bottomside ionosphere, Geomagnetism and Aeronomy.

Danilkin N. P., 2000: The results of the satellite radio sounding of the ionosphere below the F-layer maximum, submitted to Geomagnetism and Aeronomy.

Denisenko P. F., V. V. Sotsky, 1987: Peculiarities of inverse problems of vertical sounding of the ionosphere, Izvestiya SKNC VS, Proceedings of NCSC HS. Natural Sciences, No. 2, 59-71. (in Russian)

Denisenko P. F., N. V. Nastasyina, and V. V. Sotsky, 1998: Application of the regularization method for electron density height profile reconstruction by the data of vertical topside sounding. Geomagnetism and Aeronomy, 38, 172-179.

Jackson J. E., 1969: The Reduction of Topside Ionograms to Electron-Density Profiles. Proc. IEEE, 57, 960-976.

Jackson J. E., 1969b: Comparsions between Topside and Ground-based Soundings. Proc. IEEE, 57, 976-985.

Phaseva Ts., D. Samardziev, N. P. Benkova, N. A. Kochenova, and Yu.V. Kuchnerevskij, 1984: Observed and model N(h)-profiles for the Bulgarian region. Adv. Space Res., 4, No.1, 61-64.

Pulinets S. A., 1989: Prospects of topside sounding. WITS Handbook. In: C. H. Liu (Ed.), volume 2, Chapt. 3, published by SCOSTEP, Urbana, Il, 99-127.

Pulinets S. A. and R. F. Benson, 1999: Radio-Frequency Sounders in Space. Review of Radio Science. 